\title{
An Assessment of Active Disturbance Rejection Technique From a Theoretical Perspective
}

\author{
Deha Eker*, Necdet Sinan Özbek \\ 1* Adana Alparslan Türkeş Science and Technolohy University, Faculty of Engineering, Departmant of Energy Systems Engineering, Adana, Turkey, (ORCID: 0000- \\ 0002-8457-1438), deker@atu.edu.tr. \\ 2 Adana Alparslan Türkeş Science and Technolohy University, Faculty of Engineering, Departmant of Electrical and Electronic Engineering, Adana, Turkey, (ORCID: \\ 0000-0002-7184-9015), nozbek@atu.edu.tr.
}

(International Symposium on Multidisciplinary Studies and Innovative Technologies (ISMSIT) 2021 - 21-23 October 2021)

(DOI: $10.31590 /$ ejosat.1024241)

ATIF/REFERENCE: Eker, D. \& Özbek, N.S. (2021). An Assesment of Active Disturbance Rejection Control from a Theoritical Perspective. European Journal of Science and Technology, (29), 284-291.

\begin{abstract}
This paper discusses a recent disturbance suppression technique namely, active disturbance rejection control (ADRC) from the theoretical perspective. The technique is one of the recently applied control schemes in various sectors of industry and several areas of research. The methodology is elaborated with a theoretical perspective. Furthermore, the control techniques are categorized by some criteria. The paper aims to express the control techniques of ADRC from controller's perspective.
\end{abstract}

Keywords: Active Disturbance Rejection Control (ADRC), disturbance suppression, total disturbance, nonlinear control, robustness

\section{Aktif Bozucu Bastırma Tekniğinin Teorik Açıdan İncelenmesi}

$\ddot{\mathbf{O z}}$

Bu makale, yeni bir bozucu bastırma tekniği olan aktif bozucu bastırma kontrolünü (ADRC) tartışmaktadır. Teknik, çeşitli endüstri sektörlerinde ve çeşitli araştırma alanlarında son zamanlarda uygulanan kontrol şemalarından biridir. Metodoloji, teorik bir bakış açısıyla detaylandırılmıştır. Ayrıca, kontrol teknikleri bazı kriterlere göre sınıflandırılmıştır. Bu makale, ADRC'nin kontrol tekniklerini kontrolör perspektifinden ifade etmeyi amaçlamaktadır.

Anahtar Kelimeler: Aktif bozucu bastırma kontolü, bozucu bastırma, total bozucu, gürbüzlük

\footnotetext{
* Corresponding Author: Adana Alparslan Türkeş Bilim ve Teknoloji Üniversitesi, Mühendislik Fakültesi, Enerji Sistemleri Mühendisliği Bölümü, Adana, Türkiye, ORCID: 0000-0002-8457-1438, deker@atu.edu.tr
} 


\section{Introduction}

For control engineers, disturbances and uncertainties are major problems that may be dealt with in order to increase the performance controller performance. The control applications may suffer from several adversities such as nonlinearities, model mismatches, and load disturbances. In this case, the control scheme should be able to deal with some unexpected situations, so that the classical control schemes can lead to poor control performance for these types of applications. Hence, a controller that exhibits the lowest sensitivity to changes in the system dynamics, as well as internal/external disturbances will be suitable for industrial applications.

Although several advanced control techniques have been proposed, PID control is still constantly employed in industrial applications. The PID control parameters determine the performance of the the system which is controlled; thus, it is easy to adjust the parameters of the system even though control engineers do not have a ton of knowledge about the controlled system (T. He, Wu, Li, \& Wang, 2020). As well as the advantages of PID exist, it has some disadvantages. First, it has some limitations, so it is not always possible to observe the desired performance for complex systems. The reason for this fact that the PID method is an error feedback-based strategy means that PID only functions when the output of the systems and setpoint of the system are not the same. The derivative part of PID only provides a one-step prediction of error, so the uncertainties and disturbances may not be compensated fast enough for complex structured systems. The fundamental issues of PID can be pointed as (Han, 2009):

- A step function is frequently used to form the setpoint and step function is not good enough to observe the response of dynamic system.

- Derivative part of PID is not often implemented to the systems because of noise sensitivity (Derivative Kick)

- The integral term can cause other problems such that saturation and reduced stability margin. (Integral wind-up)

- It is not best control law for the update of the error signal and rate of change of it.

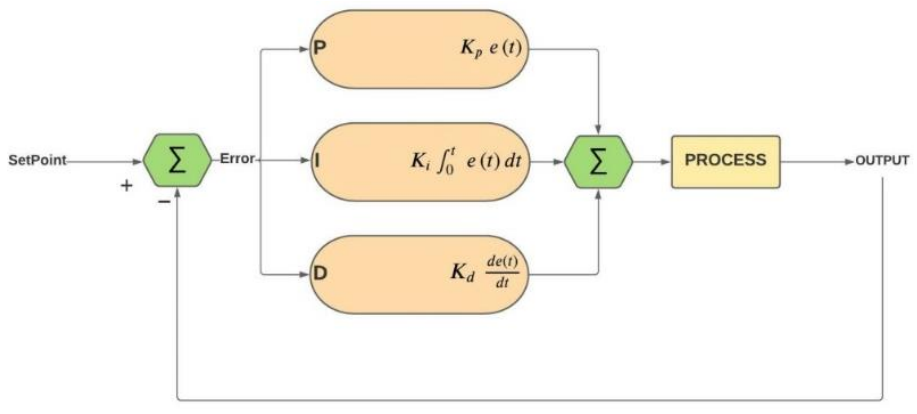

Fig. 1.PID control topology

To emphasize the recent progress on PID control, a number of studies have been discussed as follows: PID control may show insufficient results to provide the desired control response for systems comprising complex characteristics, unmodelled dynamics. Indeed, the implementation of the PID controller around operating points is a major cause of performance degradation. Bearing these observations in mind, a number of improved techniques have been proposed for the PID control. The most of the proposed techniques focus on improving the suppression performance, improving the reference tracking performance, correcting the transient, and reducing the steadystate error. Various combination of PID control with recently proposed elegant control techniques has been addressed. To mention a few, fractional-order PID (Frikh, Soltani, Bensiali, Boutasseta, \& Fergani, 2021; Kapoulea, Psychalinos, Elwakil, \& HosseinNia, 2021), event-driven PID (Åarzén, 1999; Mishra et al., 2021; Yu, Guan, Chen, \& Yamamoto, 2020), and model-free PID (Fliess \& Join, 2013; Ozbek, 2019) control are some of the efficient control strategies. However, much more efforts have to be spent for harvesting all the advantages provided by modification of PID control algorithms.

Apart from these improvements, various control schemes that can be alternative to PID control have been brought to the literature over the last few decades. Disturbance suppression techniques are very attractive to improve the robustness capability of linear and nonlinear control systems.

For instance, disturbance observer based robust control strategy has a number of prominent features. To mention a few, the main goal of the DOB is compensating the uncertainty of the controlled system acting like as an inner-controller. Hence, this controller acts in the inner-loop to control the nominal system without uncertainty and disturbance. Then, an outer-loop controller is designed to deal with nominal stability and control performance. The control block diagram of the DOB based control strategy is shown in Figure 2 (Shim, Park, Joo, Back, \& Jo, 2016). Some recent contributions on DOB techniques can be summarized as follows. A detailed survey is presented by Chen et al. (Chen, Yang, Guo, \& Li, 2016), wherein Bayrak and Efe compare the frequancy domain approaches of linear disturbance observer techniques (Bayrak \& Efe, 2021). Furthermore, a nonlinear disturbance observer control shceme is proposed in (Efe \& Kasnakoğlu, 2021), where the controlled plant has a discrete-time model.

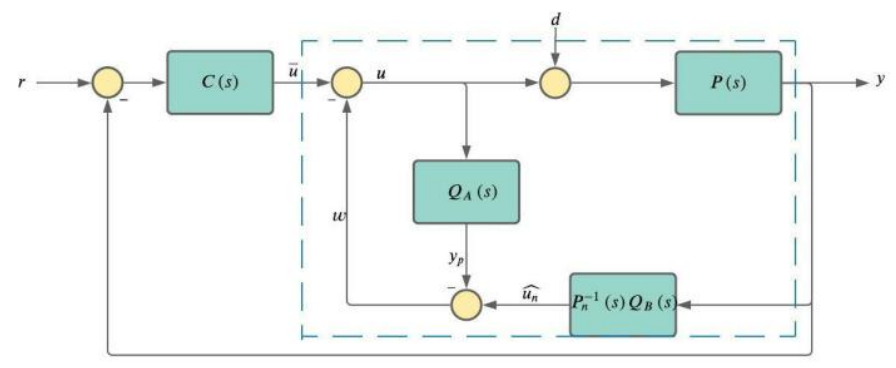

Fig. 2. Disturbance observer based control scheme

Yet another disturbance supression mechanism is the equivalent input disturbance (EID) approach, which aimt to cope with unknown uncertainties as well as disturbances. The technique is implemented by considering the difference between the actual system output and nominal plant output. A state observer acts an important role for the nominal model. The EID does not use the inverse system dynamics. In this sense, it can directly be applied to both minimum and non-minimum phase systems. It is to be noted that this design avoids the adverse influences caused by mismatched disturbances on the state estimation due to the compensation capability from the control input channel (Liu, Liu, Wu, \& Nie, 2014). The method of EID 
can also be combined with the other control mechanism such as sliding mode control method in order to increase rejection performance of disturbances. In (Jiang et al., 2019), it is clarified that SMC and EID approach are used to make disturbance rejection ability better and the simulation results performed on DC-DC buck converter supports the effectiveness of the combined method.

The method which is named as ADRC is an extraordinary and efficient technique was proposed by Han (Han, 2009). It reveals PID that is primitive but widely used method in industry is not satisfactory for new demands of industry. ADRC is now quite popular topic and has been worked by researchers almost two decades. This is because its uniqueness in concepts, ability to deal with broad range of uncertainties, good transient response.

The main idea of ADRC is to consider the internal uncertainties and external disturbances as a "generalized disturbance" and try to estimate by an extended-state-observer (ESO), and then use the estimated states in the feedback to control the disturbance. The wide range of usage of this method are robotics, motion control of various type of motors and generators, wind power generation, rocket control system, process control applications etc.

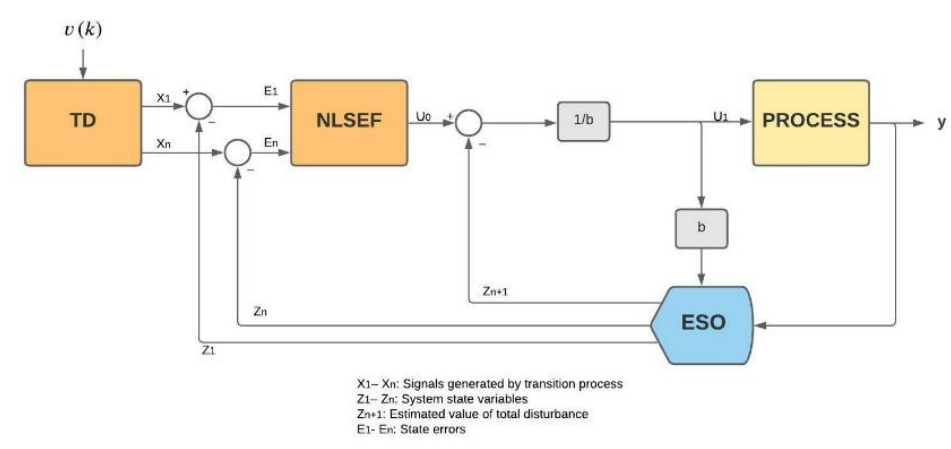

Fig. 3. ADRC general control topology

a) Tracking Differentiator: The first part of the relative algorithm is tracking differentiator that aims to to remove the effect of derivative of reference signal. It is the fact that in PID controller, derivative component is rarely used in control loop because of the sensitivity to high frequency noise and TD is used to eliminate this effect (Feng \& Guo, 2017).

b) Extended State Observer: A crucial part for the disturbance rejection algorithms is to design observer. In this context, Han J. proposes an extended state observer (ESO), which is used for estimation of disturbance in ADRC scheme. (Han, 2009). It is to be noted that the unknown dynamics of and the external disturbances are incorporated in a single term in an ESO. An in depth discussion on the ESO design is presented in (Guo \& Zhao, 2011). Furthermore, the stability issue for linear ESO is analysed in (Yoo, Yau, \& Gao, 2006).

c) Controller: This part is used to generate the control signal which is based on the difference between the estimated states and the output of TD. In various studies, it is demonstrated that the type of controller can be changed and it could be linear or nonlinear due to the system desired to be controlled (Dong et al., 2020)(Wang et al., 2020)(Sun et al., 2017).
With this motivation in mind, this study elaborates the theoretical background of active disturbance rejection control algorithm for the systems comprising disturbances and uncertainties. The control scheme is addressed with an in depth discussion. Furthermore, the present paper aims to introduce the main idea of ADRC and the recent related studies based on controllers. In Section II, theoretical background on the ADRC scheme and its components are demonstrated with a case study. In Section III, the applications of ADRC are classified according to the control algorithms. Finally, some concluding remarks are given at the end of the paper.

\section{Evaluation of Active Disturbance Rejection Control Scheme}

First, with the aim of inform clearly, it is better to use the following system (Du, Cao, She, \& Fang, 2020),

$$
\ddot{y}=b u+f
$$

where $y$ is the output, $u$ is the input of the plant, $b$ is the input parameter, and $f$ is a total disturbance, which involves the external disturbances. In order to make state space possible, the states are considered as $x_{1}=y, x_{2}=\dot{y}, x_{3}=f$

$$
\begin{aligned}
& \dot{x}=A x+B u+B_{f} h \\
& y=C x
\end{aligned}
$$

could be evaluated where,

$$
A=\left[\begin{array}{lll}
0 & 1 & 0 \\
0 & 0 & 1 \\
0 & 0 & 0
\end{array}\right], B=\left[\begin{array}{l}
0 \\
b \\
0
\end{array}\right], B_{f}=\left[\begin{array}{l}
0 \\
0 \\
1
\end{array}\right], C=\left[\begin{array}{lll}
1 & 0 & 0
\end{array}\right]
$$

It should be pointed out that $\dot{f}=h$ is assumed due to the simplification. After this an ESO (Extended State Observer) should be designed in order to make the estimations of the states. (Du, Cao, She, \& Fang, 2020),

$$
\begin{aligned}
& \dot{\hat{x}}=A \hat{x}+B u+L C(y-\dot{y}) \\
& \hat{y}=C \hat{x}
\end{aligned}
$$

where $L$ is the observer gain and $L=\left[\beta_{1} \beta_{2} \beta_{3}\right]$ Because of observability of the system (2) is satisfied, the selection of $L$ should be convenient such that estimated states converge to the actual states. $L$ can be selected as following,

$$
L=\left[\begin{array}{lll}
3 w_{0} & 3 w_{0}^{2} & w_{0}^{3}
\end{array}\right]^{\mathrm{T}}
$$

where $w_{0}$ is the bandwidth of the observer. Assume the derivative of $f$ is bounded and large enough $w_{0}$ implies that,

$$
\hat{x}_{3} \approx f
$$


The ESO (Extended State Observer) can also named as linear extended state observer (LESO) which $L$ is considered as linear gain of the observer. Using (5) the input signal $u$ can be organized as,

$$
u=u_{f}-\frac{\hat{x}_{3}}{b}
$$

By using (5), and then substituting (6) into (1) results

$$
\ddot{y} \approx u_{f}
$$

The function of ADRC is supposed to, by estimating and compensating the unmodelled dynamics and uncertainities of system, help the control engineers to examine a complex system as a simple dynamic model. The advantage of ADRC is that when only the order of the plant and the approximate value of the input parameter are sufficient, feedback control can be designed for the simple dynamic model.

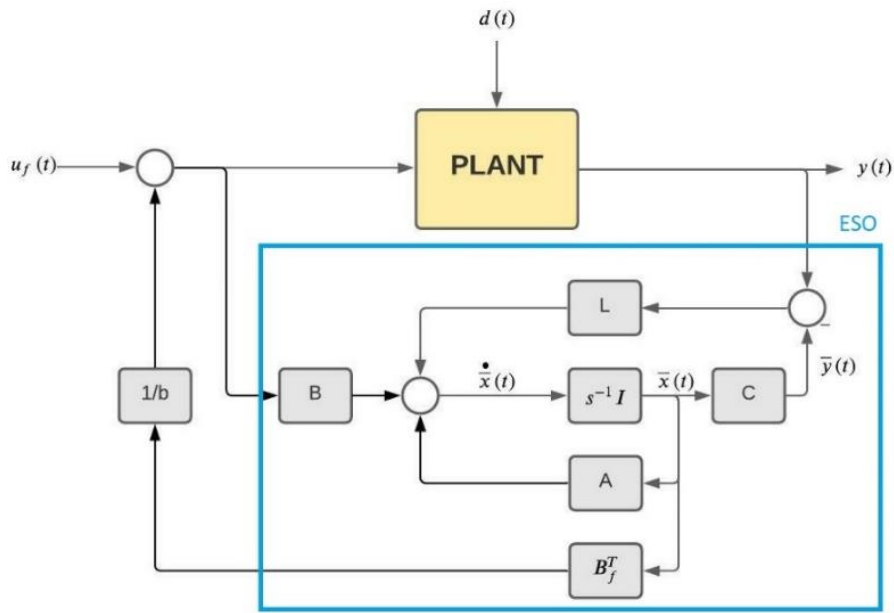

Fig. 4.Detailed diagram of Extended State Observer of an ADRC-based system.

However, the implementation of model may have its own limitations. The bandwidth of ESO is chosen well enough in order to overcome the issue of compensating the unmodelled dynamics even though practical issues may limit it.

\subsection{Case Study for ADRC}

A first order plant is used with a DC gain, $K$, and time constant, $T$ as follows, (Herbst, 2013)

Then we can get

$$
\dot{y}=b u+f
$$

where $b$ is the input parameter, $u$ is the input of the plant, $y$ is the output of the plant and $f$ is the generalized disturbance. From the plant model it is deduced that $b=K / T$. Then the system must be represented in state space where the states and system equation can be written as,

$$
\begin{aligned}
\dot{x} & =A x+B u+B_{f} h \\
y & =C x \\
x_{2} & =f \\
x_{1} & =y
\end{aligned}
$$

$\dot{f}=h$ is used for simplication and the matrices of the system are,

$$
A=\left[\begin{array}{ll}
0 & 1 \\
0 & 0
\end{array}\right], B=\left[\begin{array}{l}
b \\
0
\end{array}\right], B_{f}=\left[\begin{array}{l}
0 \\
1
\end{array}\right], C=\left[\begin{array}{ll}
1 & 0
\end{array}\right]
$$

For the simulation, Luenberger observer is used to estimate the states. The observer parameters are:

$$
A-L C=\left[\begin{array}{ll}
-l_{1} & 1 \\
-l_{2} & 0
\end{array}\right], B=\left[\begin{array}{l}
b \\
0
\end{array}\right], L=\left[\begin{array}{l}
l_{1} \\
l_{2}
\end{array}\right]
$$

According to observer function, the estimated states can be written as, $\hat{x}_{1}=\hat{y}$ and $\hat{x}_{2}=\hat{f}$. In order to give the detail,

$u(t)=\frac{u_{0}(t)-\hat{f}(t)}{b}, \quad u_{0}(t)=K_{p} .(r(t)-\hat{y}(t))$

where $u_{0}(t)$ is the output of a linear proportional controller and according to the Figure 5 it is deduced that $K_{p}$ acts on $\hat{y}$. The $u(t)$ is chosen such that the linear controller has an effect on an integrator process if equality of $\hat{f} \approx f$ is satisfied. Then it can be shown that:

$$
\dot{y}=(f(t)-\hat{f}(t))+u_{0}(t) \approx u_{0}(t)
$$

If the equality of $\hat{y} \approx y$ holds, it is obtainable that $s^{C L}=$ $-K_{p}$. If observer and disturbance rejection work properly, $K_{p}$ can be calculated from desired first order system just single time, in any case of parameters of process in respect to settling time:

$$
K_{p} \approx \frac{4}{T_{\text {settle }}}
$$

Observer gains are still needed to specified and its dynamics must be fast enough. So, the observer pole can be selected as:

$$
s^{E S O} \square 10 \cdot s^{C L}, s^{C L}=-K_{p}
$$

By using $(A-L C)$ matrix which determines the error dynamics of observer, by calculating determinant and equalize the characteristic polynomial the gains can be calculated as:

$$
l_{1}=-2 \cdot s^{E S O}, l_{2}=\left(s^{E S O}\right)^{2}
$$




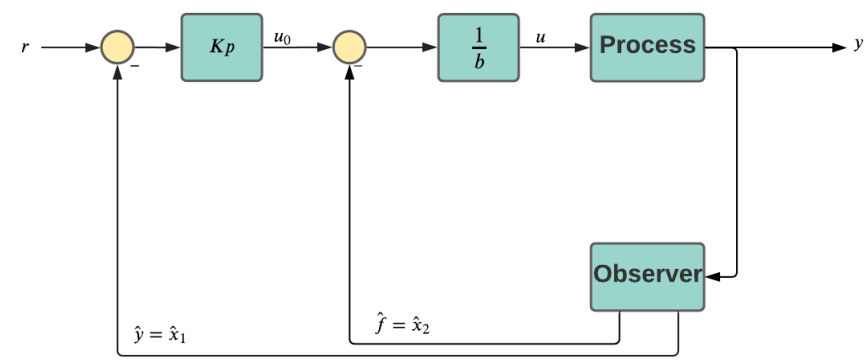

Fig. 5.Control Loop Structure with ADRC for a first order process.

The simulation study is carried out by Matlab/Simulink and steps above are followed to implement the simulation study. The parameters for first order system in equation (9) selected as $K=$ $1, T=1, T_{\text {settle }}=1$ second and then by using these parameters proportional gain, poles of observers, closed loop pole and gains of observer can be calculated. Remember that $b=$ $K / T$ left unchanged in order to indicate the closed loop step response for different $K$ values, controller output and error for process output. A step function is used for reference signal and controller of system was designed only one time in order to demonstrate the sensitivity of process parameter variations.
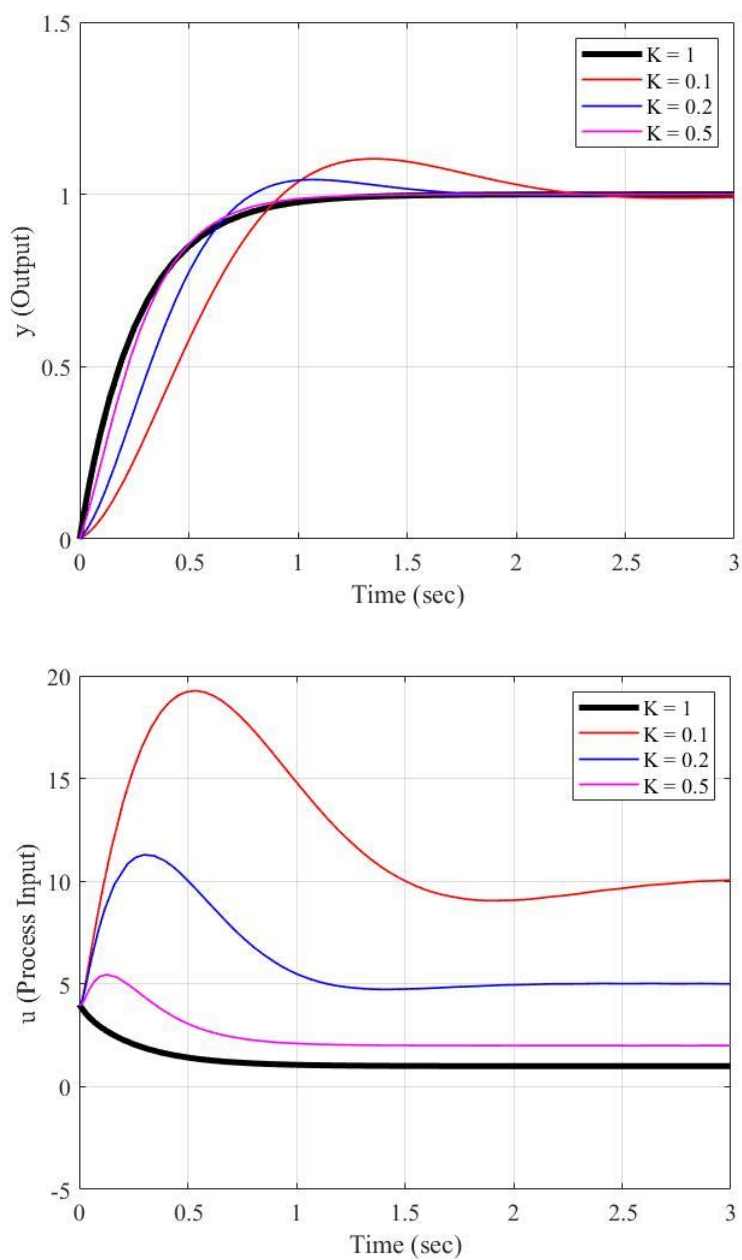

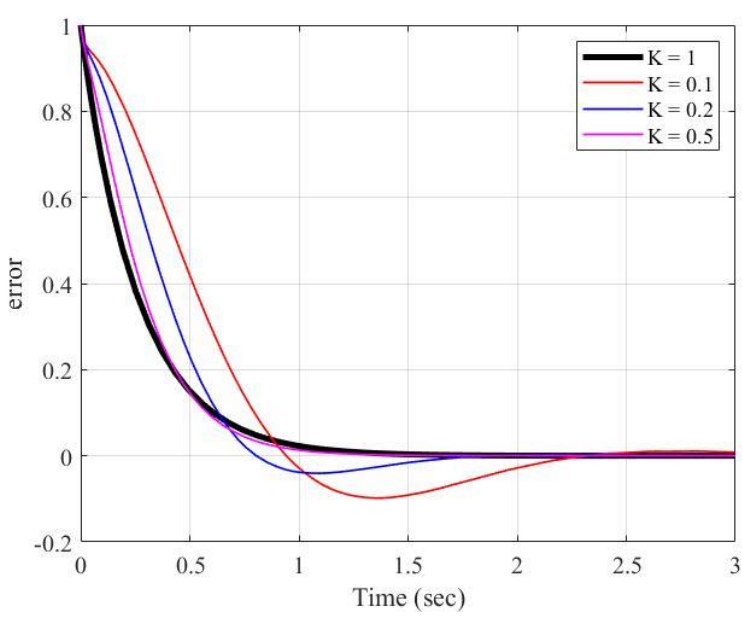

Fig. 6. The simulation results for varying $K$ values

It can be deduced that while values of $K$ get near of 1 , the less overshoot can be observed and the value of input signal gets much smaller.

\section{Control Techniques of ADRC Schemes}

\subsection{Linear Control Based ADRC Schemes}

There have been many applications of linear control based ADRC up to now. Different approaches and different perspectives have been applied to the various systems. The case of Furuta Pendulum system was one of systems that is studied on in (Ramírez-Neria, Sira-Ramírez, Garrido-Moctezuma, \& Luviano-Juárez, 2014). The combination of flatness and linear active disturbance rejection control is used to solve trajectory tracking problem of the Furuta pendulum which is no feedback linearizable system. The tangent linearization is used to linearize the system. In some practical applications there can be challenging and real time issues can be occurred in DC Motor application like sensor bandwidth effects, observer bandwidth effects etc. The assumptions of application can cause unstability (Ahi \& Haeri, 2018). For an active power filter, LADRC can be also applicable with a dual loop PI controller and LADRC controller. Comparing with ADRC, less nonlinear functions is used in this work (Wang et al., 2019). The second order LADRC and its tuning is presented based on step response curves of a controlled plant by Cui in 2020 (Cui, Tan, Li, \& Wang, 2020). Furthermore, the effectiveness of the theory is supported with a practical temperature control experiment. LADRC is also applicable on bus voltage filtering of synchronous generators (Xuesong Zhou, Liu, Ma, \& Wen, 2020).

DC bus voltage signal is necessary to used in feedback but it contains some disturbances. To make the existing ADRC in system better the influence of bus voltage filtering is also considered and turned to a state variable to use in ESO. Another tuning method of second order LADRC with relay feedback method makes the tuning part simpler. Because one of the reasons of LADRC is the fact that tuning part is more complex than regular PID. Also, without knowing the information of controlled plant, this method is also feasible (Cui, Tan, Li, Wang, \& Wang, 2020). Yet another recent work addresses the combination of PD and Luenberger obser to construct an ADRC scheme for a linear ultrasonic motor (Garrido \& Luna, 2021). Another interesting work presented by Wang demonstrates the design and tuning of linear active disturbance rejection 
controller (LADRC) for the oscillatory systems with large time delays (Wang, Tan, Cui, Han, \& Guo, 2021), wherein secondorder and third-order oscillatory systems are employed. A further research elaborates three phase voltage source PWM rectifier problem, wherein dual PI loop control method lacks voltage loop and current loop disturbance rejection. With this motivation in mind, a LADRC is proposed to enhance the tracking capability and disturbance rejection performance. Moreover, the total harmonic distortion in rectifier is less than from PI control $(\mathrm{H}$. He, Si, Sun, Liu, \& Li, 2020).

\subsection{Non-Linear Control Based ADRC Schemes}

Sliding mode control (SMC), known as a well-known robust control technique, has been successfully applied in many engineering fields for its robustness against external disturbances. SMC has been the subject of various researches in the last decades because it is insensitive to uncertainties and suppresses external disturbances. For instance, sliding mode control for an UAV is presented in (OZBEK et al.) to improve the attitude performance of the quadrotor. Sliding mode control provides desired dynamic behavior when appropriate conditions such as sliding and reaching conditions are met. Model uncertainties and disturbances cannot degrade the stability of the system when the system on sliding surface. Thus, SMC based ADRC schemes have been widely used in aerospace (Chen, $\mathrm{Li}$, \& Song,2017), power electronics (Liu et al., 2017) and other fields. With this motivation in mind, a robust ADRC method with SM component to improve the controller performance of an induction motor is proposed.

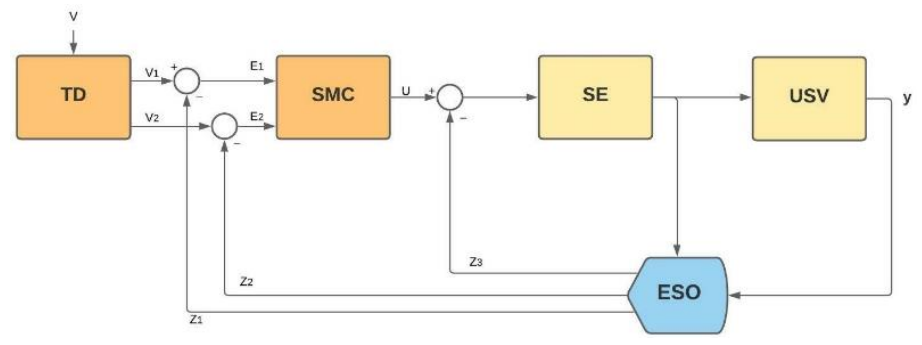

USV: Unmanned Surface Vessel

SMC: Sliding Mode Controller

TD: Tracking Differentiator

SE: Steering Gear System

Fig. 7. Sliding mode control based ADRC scheme

The comparison between the proposed ADRC method and classic ADRC method have been made to clarify the overcoming of two serious limits of ADRC which are the uncertainty in the knowledge of control gains and deterioration of performance of ADRC because of non-null estimation of error of total disturbance (Alonge, Cirrincione, D'Ippolito, Pucci, \& Sferlazza, 2017). Unmanned surface vessels are another field which have maneuvering problems while sailing and ADRC method is used to overcome these issues. In (Dong, Huang, \& Zhuang, 2020) heading angle controller is designed with an improved sliding mode active disturbance rejection control method by using Levant TD as sliding mode tracking differentiator and improved ADRC is applied for the real time estimation. By doing this the chattering problem of SMC is eliminated. For a permanent magnet synchronous machine ADRC is used to estimate the speed of machine and act as an input for a novel sliding mode observer (Chen Wei, Chen Yankun, Li Hongfeng, \& Song Zhanfeng, 2012). The effect of e-ISSN: 2148-2683 load in speed in loop is regarded as external disturbance and it is well compensated. For underactuated ships, course and path following simulation is observed by ADRC with SMC. The simulations of kinematic model of a training ship to verify the robustness and stability ( $\mathrm{Li}, \mathrm{Li}, \mathrm{Li}, \&$ Shen, 2016). For a marine current energy turbine is also a field which the SMC based ADRC method can be applied such as in (Xiangyang Zhou, Wang, \& Diallo, 2020).

\subsection{Intelligent and Fractional-Order Control Based ADRC Schemes}

Yet another motivation on the design of ADRC scheme is to integrate intelligent based control systems. Intelligent methods provide an important advantage especially for the control of systems with complex dynamics. The intelligent control techniques improve the robustness performance of the system without exact model information.

Fractional-order control is one of the most exciting topics in the control engineering framework; however, the ADRC based schemes based on fractionaol-order controllers' remains to be challenging. Thus, several papers attemp to give a satisfactorily answer to the possible usage of fractional operators in the controller part of an ADRC structure.

\section{Conclusions and Recommendations}

Although many disturbance suppression techniques have been developed in the literature, this study specifically focuses on active disturbance rejection control scheme. A comparison of several types of advanced controllers enables us to identify special characteristics and to determine the strengths and weaknesses of each control scheme. Several issues are still under research. For example, the system robustness of the proposed control strategy will be elaborated on the additive and multiplicative uncertainty aspect. Notwithstanding the numerous researches, ADRC remains an issue of paramount relevance in control theory. Furthermore, it is still necessary a great effort to enhance the control performance with active disturbance rejection control schemes subject to uncertainties, perturbations, and time-delay. Future works will concern the application of the present control strategies to a number of different industrial control systems comprising delays and uncertainties.

\section{Acknowledge}

The authors would like to thank the anonymous reviewers for careful reading of the manuscript and for their valuable comments.

\section{References}

Åarzén, K.-E. (1999). A simple event-based PID controller. IFAC ProceedingsVolumes,32(2),8687-8692. https://doi.org/10.1016/S1474-6670(17)57482-0

Ahi, B., \& Haeri, M. (2018). Linear Active Disturbance Rejection Control from the Practical Aspects. IEEE/ASME Transactions on Mechatronics, 23(6), 2909-2919. https://doi.org/10.1109/TMECH.2018.2871880

Alonge, F., Cirrincione, M., D’Ippolito, F., Pucci, M., \& Sferlazza, A. (2017). Robust Active Disturbance Rejection 
Control of Induction Motor Systems Based on Additional Sliding-Mode Component. IEEE Transactions on Industrial Electronics,64(7),5608-5621. https://doi.org/10.1109/TIE.2017.2677298

Bayrak, A., \& Efe, M. Ö. (2021). A frequency domain comparison of disturbance observer based control schemes. Proceedings of the Institution of Mechanical Engineers, Part I: Journal of Systems and Control Engineering, 095965182110365.

https://doi.org/10.1177/09596518211036597

Chen, W.-H., Yang, J., Guo, L., \& Li, S. (2016). DisturbanceObserver-Based Control and Related Methods-An Overview. IEEE Transactions on Industrial Electronics, 63(2),1083-1095. https://doi.org/10.1109/TIE.2015.2478397

Chen Wei, Chen Yankun, Li Hongfeng, \& Song Zhanfeng. (2012). Sensorless control of permanent magnet synchronous motor based on sliding mode observer. Proceedings of The 7th International Power Electronics and Motion Control Conference, 2582-2586. https://doi.org/10.1109/IPEMC.2012.6259266

Cui, W., Tan, W., Li, D., \& Wang, Y. (2020). Tuning of linear active disturbance rejection controllers based on step response curves. IEEE Access, 8, 180869-180882. https://doi.org/10.1109/ACCESS.2020.3028459

Cui, W., Tan, W., Li, D., Wang, Y., \& Wang, S. (2020). A Relay Feedback Method for the Tuning of Linear Active Disturbance Rejection Controllers. IEEE Access, 8, 45424550. https://doi.org/10.1109/ACCESS.2019.2963419

Dong, H., Huang, H., \& Zhuang, Y. (2020). Heading Angle Controller Design of USV Based on Improved Sliding Mode Active Disturbance Rejection Control. Proceedings - 2020 Chinese Automation Congress, CAC 2020, (2), 3547-3551. https://doi.org/10.1109/CAC51589.2020.9326809

Du, Y., Cao, W., She, J., \& Fang, M. (2020). A Comparison Study of Three Active Disturbance Rejection Methods. Chinese Control Conference, CCC, 2020-July, 135-139. https://doi.org/10.23919/CCC50068.2020.9189230

Efe, M. Ö., \& Kasnakoğlu, C. (2021). A nonlinear disturbance observer scheme for discrete time control systems. Turkish Journal of Electrical Engineering and Computer Sciences, 29(2), 1044-1060. https://doi.org/10.3906/ELK-2005-206

Fliess, M., \& Join, C. (2013). Model-free control. International Journal of Control ,86(12), 2228-2252. https://doi.org/10.1080/00207179.2013.810345

Frikh, M. L., Soltani, F., Bensiali, N., Boutasseta, N., \& Fergani, N. (2021). Fractional order PID controller design for wind turbine systems using analytical and computational tuning approaches. Computers and Electrical Engineering, 95(June 2020), 107410 .

https://doi.org/10.1016/j.compeleceng.2021.107410

Garrido, R., \& Luna, L. (2021). Robust ultra-precision motion control of linear ultrasonic motors: A combined ADRCLuenberger observer approach. Control Engineering Practice,111(March),104812.

https://doi.org/10.1016/j.conengprac.2021.104812

Guo, B.-Z., \& Zhao, Z.-L. (2011). Extended State Observer for Nonlinear Systems with Uncertainty. IFAC Proceedings Volumes,44(1),1855-1860.

https://doi.org/10.3182/20110828-6-IT-1002.00399

Han, J. (2009). From PID to active disturbance rejection control. IEEE Transactions on Industrial Electronics, 56(3), 900906. https://doi.org/10.1109/TIE.2008.2011621

He, H., Si, T., Sun, L., Liu, B., \& Li, Z. (2020). Linear Active
Disturbance Rejection Control for Three-Phase VoltageSource PWM Rectifier. IEEE Access, 8, 45050-45060. https://doi.org/10.1109/ACCESS.2020.2978579

He, T., Wu, Z., Li, D., \& Wang, J. (2020). A tuning method of active disturbance rejection control for a class of high-order processes. IEEE Transactions on Industrial Electronics, 67(4),3191-3201. https://doi.org/10.1109/TIE.2019.2908592

Kapoulea, S., Psychalinos, C., Elwakil, A. S., \& HosseinNia, S. H. (2021). Realizations of fractional-order PID loop-shaping controller for mechatronic applications. Integration, 80(March),5-12. https://doi.org/10.1016/j.vlsi.2021.04.009

Li, R., Li, T., Li, X., \& Shen, H. (2016). Path following for underactuated ships control and simulation based on active disturbance rejection with sliding mode control. ICIC Express Letters, 10(6), 1415-1420.

Liu, R.-J., Liu, G.-P., Wu, M., \& Nie, Z.-Y. (2014). Disturbance rejection for time-delay systems based on the equivalentinput-disturbance approach. Journal of the Franklin Institute, 351(6),3364-3377. https://doi.org/10.1016/j.jfranklin.2014.02.015

Mishra, S. K., Jha, A. V., Verma, V. K., Appasani, B., Abdelaziz, A. Y., \& Bizon, N. (2021). An optimized triggering algorithm for event-triggered control of networked control systems.Mathematics,9(11),1-22. https://doi.org/10.3390/math9111262

Ozbek, N. S. (2019). An Evaluation of Model-Free Control Strategies for Quadrotor Type Unmanned Aerial Vehicles. Proceedings - 2019 3rd International Conference on Applied Automation and Industrial Diagnostics, ICAAID 2019, (September),25-27. https://doi.org/10.1109/ICAAID.2019.8935001

Ramírez-Neria, M., Sira-Ramírez, H., Garrido-Moctezuma, R., \& Luviano-Juárez, A. (2014). Linear active disturbance rejection control of underactuated systems: The case of the Furuta pendulum. ISA Transactions, 53(4), 920-928. https://doi.org/10.1016/j.isatra.2013.09.023

Shim, H., Park, G., Joo, Y., Back, J., \& Jo, N. H. (2016). Yet another tutorial of disturbance observer: robust stabilization and recovery of nominal performance. Control Theory and Technology, 14(3),237-249. https://doi.org/10.1007/s11768016-6006-9

Wang, Y., Tan, W., Cui, W., Han, W., \& Guo, Q. (2021). Linear active disturbance rejection control for oscillatory systems with large time-delays. Journal of the Franklin Institute, 358(12),6240-6260. https://doi.org/10.1016/j.jfranklin.2021.06.016

Yoo, D., Yau, S. S.-T., \& Gao, Z. (2006). On convergence of the linear extended state observer. 2006 IEEE Conference on Computer Aided Control System Design, 2006 IEEE International Conference on Control Applications, 2006 IEEE International Symposium on Intelligent Control, 1645-1650.https://doi.org/10.1109/CACSD-CCAISIC.2006.4776888

Yu, H., Guan, Z., Chen, T., \& Yamamoto, T. (2020). Design of data-driven PID controllers with adaptive updating rules. Automatica, 121,109185. https://doi.org/10.1016/j.automatica.2020.109185

Zhou, Xiangyang, Wang, T., \& Diallo, D. (2020). An active disturbance rejection sensorless control strategy based on sliding mode observer for marine current turbine. ISA Transactions, $(\mathrm{xxxx})$. https://doi.org/10.1016/j.isatra.2020.05.027

Zhou, Xuesong, Liu, M., Ma, Y., \& Wen, S. (2020). Improved 
linear active disturbance rejection controller control considering bus voltage filtering in permanent magnet synchronous generator. IEEE Access, 8, 19982-19996. https://doi.org/10.1109/ACCESS.2020.2967395

Dong, H., Huang, H., \& Zhuang, Y. (2020). Heading Angle Controller Design of USV Based on Improved Sliding Mode Active Disturbance Rejection Control. Proceedings - 2020 Chinese Automation Congress, CAC 2020, 2, 3547-3551. https://doi.org/10.1109/CAC51589.2020.9326809

Feng, H., \& Guo, B. Z. (2017). Active disturbance rejection control: Old and new results. Annual Reviews in Control, 44, 238-248. https://doi.org/10.1016/j.arcontrol.2017.05.003

Jiang, Z., Zhou, L., Zhang, Z., Jiang, F., \& Cheng, L. (2019). An equivalent-input-disturbance-based sliding mode control approach for dc-dc buck converter system with mismatched disturbances. Chinese Control Conference, CCC, 2019-July, 639-644. https://doi.org/10.23919/ChiCC.2019.8865812

Sun, G., Li, Y., Jin, W., \& Bu, L. (2017). A Nonlinear ThreePhase Phase-Locked Loop Based on Linear Active Disturbance Rejection Controller. IEEE Access, 5, 21548-
21556. https://doi.org/10.1109/ACCESS.2017.2759166

Wang, Y. W., Zhang, W. A., \& Yu, L. (2020). A Linear Active Disturbance Rejection Control Approach to Position Synchronization Control for Networked Interconnected Motion System. IEEE Transactions on Control of Network Systems, 7(4), 1746-1756. https://doi.org/10.1109/TCNS.2020.2999305

Du, Y., Cao, W., She, J., \& Fang, M. (2020). A Comparison Study of Three Active Disturbance Rejection Methods. Chinese Control Conference, CCC, 2020-July, 135-139. https://doi.org/10.23919/CCC50068.2020.9189230

Wang, R., Hu, B., Sun, S., Man, F., Yu, Z., \& Chen, Q. (2019). Linear Active Disturbance Rejection Control for DC Side Voltage of Single-Phase Active Power Filters. IEEE Access, 7,73095-73105. https://doi.org/10.1109/ACCESS.2019.2920626

Herbst, G. (2013). A Simulative Study on Active Disturbance Rejection Control (ADRC) as a Control Tool for Practitioners. Electronics, 24(4), 246-279. https://doi.org/10.3390/electronics2030246 